\title{
Penile agenesis
}

INSERM

\section{Source}

INSERM. (1999). Orphanet: an online rare disease and orphan drug data base. Penile agenesis. ORPHA:49

Penile agenesis is a rare urogenital tract malformation characterized by complete congenital absence of the phallus. It is usually accompanied by a well-developed scrotum and presence of a skin tag at the anal verge (with or without a urethral meatal opening within it). Often, other genitourinary (e.g. cryptorchidism, renal agenesis and dysplasia, urinary reflux, prostate agenesis) as well as non-genitourinary abnormalities (including skeletal and neural disorders, anal stenosis, imperforate anus, cardiac defects) are associated. 